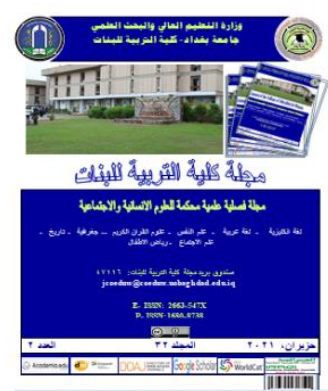

Received: March 5, 2021

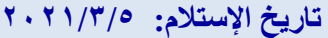

Accepted: April 11, 2021

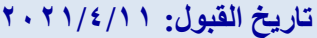

Published: June 28, 2021

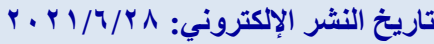

DOI: http://doi.org/ 10.36231/coedw.v32i1.1501

\section{Persuasive Strategies in WHO COVID-19 Virtual Press Conferences}

Firas M. Hammad ${ }^{1}$ and Juma'a Q. Hussein ${ }^{2}$ Department of English, College of Education for Humanities, University of Anbar ${ }^{1 \& 2}$ fir19h1011@uoanbar.edu.iq jumaqadir@yahoo.com

\section{Abstract}

Persuasion is an indispensable skill in everyday life; that is why, it has aroused researchers' interest. This study aims to investigate the most frequently used persuasive strategies in texting WHO COVID-19 Virtual Press Conferences and explore how these strategies are employed to achieve persuasive messages. To this end, a text of WHO COVID-19 Virtual Press Conferences has been chosen randomly to be analyzed based on Dillard and Shen's (2013) "Persuasive strategies in Health Campaigns". A qualitative method has been adopted in analyzing the selected data to investigate the credibility and validity of the persuasive strategies used in such a domain. Findings have shown that most of the persuasive appeals based on the adopted model are used, but in varying proportions. The total number of the persuasive strategies used in the data is (38) where the incentive appeals constitute $36 \%$ (14), the quantitative dissemination factors equal to $18 \%(7)$, the one sided-vs. two-sided messages are $18 \%(7)$, the evidence is $13 \%(5)$, the message sources are $7 \%$ (3), and the message qualities are $5 \%$ (2), respectively. These frequencies show that 'incentive appeals' are mostly used. This is because Physical health, or factors, such as the economic, legal, psychological, social, and effort are the key dimensions of the incentive appeals. Each has a positive potential and negative evaluations based on audience' predispositions. Accordingly, the field in which the persuasive appeals are used determines the frequent use of each one.

Keywords: COVID-19, Persuasive strategies, WHO Virtual Press Conferences

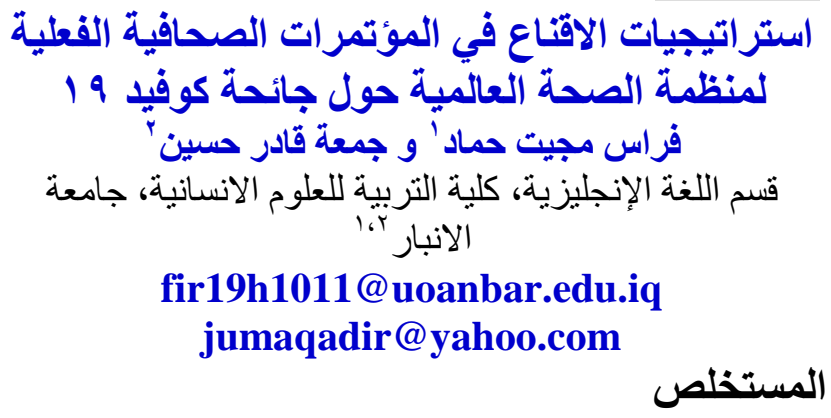

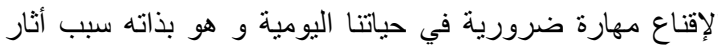

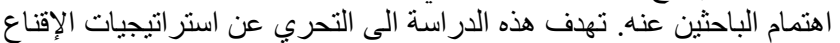

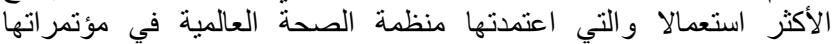

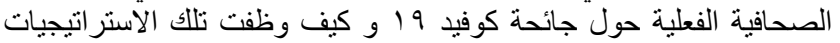

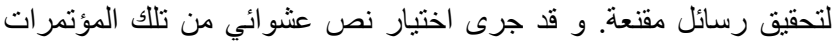

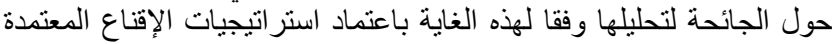

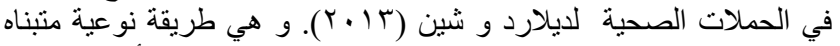

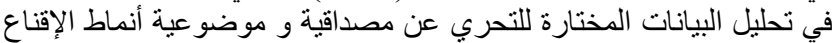

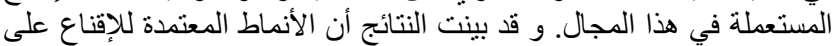

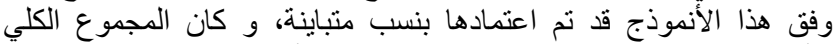

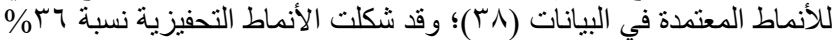

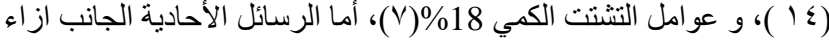

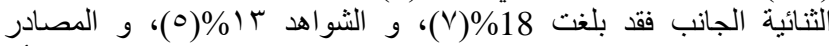

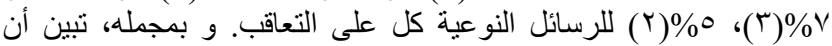

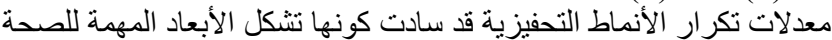

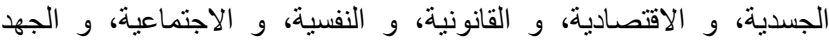

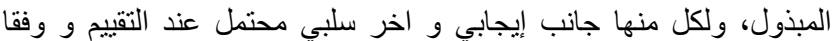

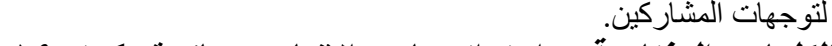
الكلمات المفتاحية: استراتيجيات الإقناع، جائحة كوفيدو 19

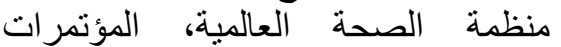
الصحافية الفعلية 


\section{Introduction}

One way of exerting influence is realized by the use of language. Success or failure to influence others is determined by one's abilities to define the language and the terms being used for persuasion. Persuasion in the social sciences is an important subject. As it is known, human beings are social beings. What has been achieved is interpersonally orchestrated through one's correspondence, psychology, social or medical organizations, political systems, business choices. Persuasion is one of the powerful tools used for achieving these alliances (Knowles \& Linn, 2008). That is; some discourses are quite persuasive while others are not. A medical speechmaker, for example, seeks to make his audience change their behavior in the interest of their health. What is really crucial about it is that some medical discourses or one of their parts face such a problem of not achieving what must be achieved that needs closer attention. From this aspect, some discourses succeed to reach this goal, but others fail. Apparently, the persuasiveness of a medical discourse depends extremely on the way it is built. Therefore, the issue that made one dives in this research is to perceive the different persuasive strategies that construct a powerfully convincing speech for good speakers and the ones who are capable of implanting their ideas in others' minds.

Persuasion has been dealt with from different aspects. Since the subject of persuasion is broad, no one can cover all its aspects. Accordingly, many researchers have tried to bridge the gaps that have not yet been tackled (Al-Shekhly \& Mohsin, 2013; Kouzouloglous, 2015; Aditama, 2016; Ghazani, 2016; Khalil, Islam, Chattha \& Qazalbash, 2017; Janam, 2019; Abu Ruuman, 2019; \& Waad \& Al-Bahrani, 2020). For instance, Al-Shekhly and Mohsin (2013) investigated the persuasive strategies used in blurbs. They adopted Valor's (2005) model of persuasion. They provided evidence that blurbs constitute a genre characterized by its own communicative purpose to persuade readers to buy the book by describing its contents and praising its qualities.

From critical discourse analysis perspective, three researchers tried to tackle persuasion in different discourses. Kouzouloglous (2015) investigated aspects of persuasion in Tony Blair's victory speech, Khalil et al. (2017) studied the persuasive strategies in Imran Khan's Election Speech, and Janam (2019) studied persuasive strategies used by Hillary Clinton and Donald Trump in their political speeches during the presidency election period. Those political leaders experienced different strategies in their speeches. Other researchers utilized Aristotle's persuasive strategies. For example, Aditama (2016) tackled persuasion from a pragmatic aspect in International Journals. In his analysis, he adopted Hyland's hedges theory to investigate the hedging strategies in persuasive sentences.

Aristotle's persuasion appeals were also employed by Ghazani (2016) to investigate the persuasive strategies used in the field of American presidential speeches. Abu Ruuman (2019) tackled persuasion via using rational appeals, credibility appeals, and affective appeals. These persuasive strategies were applied to tackle the persuasive strategies used in Friday Sermons of Dr. Mohammad Rateb AlNabilsi. Finally, Waad and Al-Bahrani (2020) utilized nonverbal techniques suggested by several scholars to explore the role of nonverbal language in increasing tourists' sense of persuasion in general.

Consequently, although the subject has been investigated from different perspectives, it has not yet been addressed adequately in health sector, such as health campaigns. In other words, little or few studies have been conducted to address this issue in health campaigns namely COVID-19 Pandemic. Therefore, the present study is an attempt to tackle an aspect that has not been tackled yet. It is designed to extend a reader's knowledge of the persuasive strategies used in the health campaigns of 'WHO COVID19 Virtual Press Conferences'. That is, this 
study is an attempt to explore the most identifiable techniques of persuasion involved in WHO COVID-19 Virtual Press Conferences to access their credibility and validity. As there are many classifications of persuasive strategies, it is argued that Dillard and Shen's (2013) persuasive strategies in health campaigns seem to be more appropriate for the present study. It is also thought that this model has not yet been used in the past studies. To this end, the study proposes two research questions:

1. What are the persuasive strategies most frequently used in WHO COVID-19 Virtual Press Conferences?

2. How are persuasive strategies employed to foster the persuasive process?

\section{Theoretical Framework}

\subsection{Some Definitions of Persuasion}

Various definitions of persuasion have been presented by many scholars. O'shaughnessy and O'shaughnessy (2004) defined persuasion as "the process of trying to alter, modify or change the saliency of the values, wants, beliefs and actions of others. Social life is dominated by conscious or unconscious, forceful or tangential attempts at persuasion"(p.5). They elaborated that the reason behind this definition is that a commonality of values and belief eases is getting along with others and there is a stress on this end. They also asserted that "if we all understand everything in the same way, there would be no point in communicating at all" (p.5).

Smith (2014) defined persuasion as "another form of mind control that is similar to manipulation in that it works in order to influence the behaviors, motivations, intentions, attitudes, and beliefs of the subject"(p.41). He asserted that there are two main types of persuasion: 'systematic persuasion' and 'heuristic persuasion'. Systematic persuasion is the procedure of changing the attitudes or beliefs via appeals to logic and reason. On the other hand, heuristic persuasion is the process where attitudes and beliefs are changed due to an appeal to habits or emotions. Van Dijk (2006, as cited in Pelclova'and $\mathrm{Lu}, 2018$ ) defined persuasion in a different way, "as a social phenomenon that consists in interaction between social actors (the persuader as the initiator of a persuasive communication and the addressee or audience as the target of persuasion) in a public environment"(p.1). In a more complicated way than other scholars, Charteris -Black (2011) defined persuasion as "a multi-layered discourse that is the outcome of a complex interaction between intention, linguistic choice and context"(p.51).

In a different view from O'shaughnessy and O'shaughnessy's (2004), Noshtine (1989) defined persuasion as "any attempt to influence the actions or judgments of others by talking or writing to them"(p.3). However, O'shaughnessy and O'shaughnessy's (2004) argued that persuasion is different from influence. Although persuasion is a way to influence, not all types of influence are persuasion. They justified that "people can influence the values, beliefs, wants, actions of others without doing any deliberate try to do so"(p.6). Hence, one may manipulate others to act in ways that are hurtful to our interests, like when we make them hate us. In comparison, persuasion attempts purposefully to model ideals, opinions, and behavior in a trend preferred by the persuader. In addition, the word 'influence' does not bear the concept of expected effort to affect others. There is another regard in which persuasion, in the general sense, is different from influence. One can affect others and the latter and affect the former without any trust being involved. Moreover, without some trust, no sort of persuasion can get off the ground. Such an issue was addressed earlier by Aristotle in his theory of persuasion that the coming section will address briefly.

\subsection{Aristotle's Theory of Persuasion}

Aristotle was one of the philosophers of Greece who lived in the $4^{\text {th }}$ B.C. He, as an effective thinker, wrote on many topics, from logic and ethics to metaphysics and biology. One field in which Aristotle was especially interested in was rhetoric. That is, the art of persuasion. He wrote an entire book entitled "On Rhetoric" in 
which he clarified his theories of persuasive speaking and writing. Most significantly, he explained the concepts of logos, pathos and ethos, as primes for a persuasive language (Kennedy,1963). One can further learn about the art of persuasive language from these three concepts. They can be facilely applied to one's persuasive speaking and writing, as illustrated below:

\section{(a) Logos (Reason)}

Originally, it is a Greek word that could mean word, speech, argument, and reasoning (Worthington, 1994). Logos, according to Kennedy (1963), is an obscure or mystical concept which may indicate concretely a word, words, or even an entire oration. It may also be used abstractly to refer to the meaning beyond words or expressions or the power of thoughts and organizations or the national principles of the universe or the will of God [Allah] (may His majesty be glorified!). It involves man's thoughts and his functions in society, and it further comprises artistic creativity and the strength of personality. More recently, logos is defined by (O'Hair, Wiemann, Mullin, \& Teven, 2015) as a term used to refer to persuasive appeals pointed to the audience' reasoning on a topic. Reasoning is the line of thoughts one uses to make judgments on the basis of facts and inferences from the world one lives in. This basic human ability lies at the heart of reasonable proof: when one presents his/her pieces of evidence to the audience, hoping that the listeners will obtain the same logical conclusion as s/he has, one is appealing to his/her reasons.

\section{(b) Pathos (Passion)}

It is the root of the word "sympathy" (Heinrichs,2007). Pathos is the second Aristotle's kind of proof that is coming from putting the audience into a specific state of mind (Kennedy,1963). Charteris -Black (2011) defined the classical concept of Pathos as the speaker's ability of motivating human emotions. Aristotle (Rhetoric 1356a, 1377b, as cited in Worthington, 1994) defined pathos broadly as "creating a certain disposition in the audience"(p.26). O'Hair et al., (2015) explained Aristotle's definition and stated that pathos requires creating a specific disposition in the audience, often through language and disposition that are filled with strong emotions. Although emotions can be an influential means of motivating an audience, emotional appeals may be not impressive if used in isolation-especially if the emotions one arouses is fear. Fear appeals are normally only effective if the speaker can make the audience see that the threat as earnest, that is probable to happen to them; and that there is a certain action they can talk to evade the threat.

Correspondingly, the proposal is that the emotions involved in response to "emotionbased proofs form affirmations" of one or more premises, are part of an implied inference to a conclusion. Therefore, a sequence of mental states is gotten as follows:

1-"I register evidence that Jack is a dangerous character".

2-"I feel afraid of Jack (I feel that Jack is a dangerous character).

3-"I believe Jack is guilty of assault."

This sequence of mental states characterizes the following sequence in those states:

1-"Evidence for Jack: Jack is a dangerous character." "And this evidence is reputed."

2-"Jack is a dangerous character."

3-"Jack is guilty of assault."

In other words, the proof begins from reputed premises; these premises grant epistemic good influence on the conclusion due to the relation in which they stand to it. The proof aims at persuading the listener to consent the conclusion due to these features (Dow, 2015, p.101).

\section{(c) Ethos (Character)}

Ethos, originally, is a Greek word which means 'habitat'-the environment which animals and people live in. This makes no sense unless one thinks about the meaning of "ethics"; a direct etymological descendant of ethos. An ethical person suits his audience' rules and values in a way similar to a penguin suits the special habitat 
of an iceberg. That is, Ethos has to do with a person's capability to fit in with individuals' expectations. Ethos utilize the persuader's personality, reputation, and capability of looking trustworthy (Heinrichs, 2007). Kennedy (1963) defined Ethos which is the third form of Aristotle's artistic proof as the speaker's heavily dependence on his personal authority and the impression he gives. O'Hair et al. (2015) stated that Aristotle confirmed that 'speech making' should assert the quality and effect of ideas, but he realized that issues like a speaker's character, competence, goodwill and trustworthiness play a vital role in how well the audience pays attention and accepts the message. He referred to this impact of the speaker as the speaker's credibility.

O'Hair et al., (2015) asserted that there are additional ways in which speakers can make use of Ethos. For instance, audience attend to be more easily convinced by speakers who are similar to them in attitudes, background, goals and interests. One must trust the speakers he likes. However, if an interlocutor is similar to us and very lovable but unprepared, disorganized, or uninformed that is not competent, we possibly will not find him or her to be particularly trustworthy. Audience also attend to react to speakers' physical attractiveness; that is, if evaluated positively, audience helps speakers who seem more loveable and credible and can positively affect attitude and behavior change (O'Hair et al., 2015).For example, Baker and Churchily (1977), and Teven and Winters (2007) stated that studies in marketing and advertising affirm that physically attractive models are more influential at selling goods than their less attractive counterparts; when the model is female and the audience is male, it will be more effective on the act of persuasion. In contrast, Petty and Cacioppo (1986) claimed that attractiveness does not always procure to persuasion, but it does if receivers depend on peripheral processing.

\subsection{The Adopted Model}

The model adopted in this study is Dillard and Shen's (2013) "Persuasive Strategies in
Health Campaigns". A persuasive message is a principal component in the content of health campaigns. Campaigns feature convincing appeals derived from the matrix or health behavior models of McGuire, such as the planed behavior theory. Such theories have detailed methods of argumentation to persuade the audience to choose the advised action or prevent the forbidden actions. The simple persuasive mission adopted by the campaign reinforces "existing predispositions (e.g., strengthening a positive attitude, promoting post behavior consolidation, and motivating behavioral maintenance over time") in order to convince the target audience to adopt the recommended behavior (Dillard \& Shen, 2013, p.285).

However, health campaigns are in need of changing attitudes and behaviors of their target audience, the campaigns makers face a clear challenge in fulfilling influence. Since a lengthy campaign typically requires a broad arrangement of persuasive messages, campaigns makers have spacious opportunity to build and refine various appeals based on motivational incentives attended to impact attitudes and behaviors. Six persuasive strategies are proposed to be adopted in health campaigns in order to influence the target audience. They are as follows:

1. Incentive Appeals: Message framing is the first strategic decision in making and delivering persuasive appeals on health topics. Strategists face a simple option between motivating the audience with prospects of achieving outcomes that are typically deemed beneficial or unfavorable for the most direct attempts to influence health habits. In gainframed appeals for messages, the incentive messages promise the audience that doing a healthy practice (or not doing an unhealthy practice) will either gain a desirable consequence or avoid an undesirable consequence; by contrast, loss-framed appeals for messages do the reverse.

Messages usually focus on the two components of results with an expectation value, the subjective likelihood of a result occurring and 
the level of positive or negative value of that result. "For the conventional loss-framed messages threatening undesirable consequences, the operational formula derived from the health belief model is the summation of susceptibility $x$ severity across various outcomes"(p.285).The primary goals of communication are (1) to modify expectation beliefs to a higher degree of likelihood, (2) to exacerbate valence's negativity or positivity, and (3) to improve the salience of negative or beneficial results associated with participating in prescribed activities.

The main dimensions of incentive messages involve physical health, legal, economic, social, psychological, and effort. Based on audience' predispositions, each has a prospective of positive and negative valuations. Physical health is the most commonly used dimension in health campaigns. Threats of negative value (particularly death, sickness, and injury) were more frequent than positive promises, such as well-being. There are three kinds of incentive appeals:

\section{(a) Negative Appeals}

Health campaigns depend heavily on lossframed messages that concentrate on the negative effects associated with an unhealthy activity being introduced or continued. Health messages can also pose risks of a less serious nature and offer negative motivation outside the physical health realm, instead of primarily stressing extreme fear appeals. Since there are no compelling outcomes in the health topics (e.g., low probability), the next appropriate approach is to choose a mild incentive that is highly probable. For example, minor negative physical incentives in drug campaigns may be weight gain, lack of endurance, and physiological addiction. Other messages may show: social negative incentives (e.g., alienating friends, looking uncool, losing the trust of parents, deviating from social norms or incurring peer disapproval), psychological negative incentives (e.g., feeling lazy and unmotivated, reduced ability to concentrate, low grades, making bad decisions, and losing control, as well as anxiety about being caught or suffering from harm, guilt and loss of self-respect), economic incentives (e.g., decreased job opportunities, the cumulative cost of buying drugs, fines, and inability to spend money on other requirements and desires) and legal incentives (penalties for breaching laws and standards, such as detention, loss of driver's license, or dismissal from school).

\section{(b) Positive Appeals}

In doing healthy practice or avoiding unhealthy practice, a good result can also be promised. Drug abstention messages in physical health can provide chances of a longer lifespan due to athletic success. Similarly, psychological incentives can offer results such as having power of one's life, achieving a positive self-image, or achieving one's objectives. "Social incentives" may include gaining approval and respect, being cool, forming deeper friendships, building confidence with parents, and being a good role model.

\section{(c) Multiple Appeals}

There are numerous persuasive appeals which are successful on a health subject. Thus, it is preferable for campaigners to use many various appeals rather than depending on a few of incentives. The key criteria for identifying incentives to be delivered are the promised or threatened results, the flexibility of beliefs about the probability of examining these consequences, and the possible persuasiveness of the claims that can be advanced. Including novel appeals is important in the messages of familiar health subjects to complete the standard arguments.

\section{Evidence}

When receiving threatening messages on the subject of their personal health, people appear to be defensive, which can be expressed by reaction, counter- arguing, or denial of applicability. Hence, the priority is to provide reliable evidence to support claims of susceptibility, particularly regarding the degree of risk of harmful physical consequences. Health message creators are careful to explain how the evidence is applicable to the target audience's situation and are cautious to use extreme 
arguments (e.g., implausible statistics, singular cases or controversial information). These elements might strain plausibility and arouse suspicion.

\section{One-Sided Vs. Two-Sided Campaign Messages}

A number of drawbacks perceived by the audience, especially attempts to follow healthier practices, forsake the pleasures of unhealthy practices, and hinder compliance with behavioral guidelines. The strategists handle these drawbacks by using the one-sided strategy that would continually disregard the drawbacks and present only the case that favors healthy conduct or opposes unhealthy competition. One-sided messages are mostly used in the health campaigns.

Another strategy proposed by strategists is the two-sided strategy. In the two-sided message, the components of the opposing state are tactically raised and rebated to void current suspicions and future challenges. They utilize strategies, such as disproving inaccurate information or reducing the prominent drawback.

\section{Message Qualities}

Health campaign messages require five touching message qualities in order to be persuasive. First, credibility is mostly conveyed by the trustful and competent source and supplying persuasive evidence. Second, the ideas and styles might be delivered in an attractive and entertaining way because many people consider health subjects as inherently boring. The third quality assures the option of personal and appropriate content and stylistic devices (e.g., portrayals of familiar settings, engrossing narratives, or personally tailored information), so that recipients perceive the behavioral recommendation to be relevant to their own health condition and needs. The fourth one is understandability, the presentation of health content should be simple, clear, and detailed thin order to be comprehensible and comprehensive to receivers. The fifth message quality is motivational incentives as previously explained.

\section{Message Sources}

Most health messages noticeably characterize source messengers. The messenger is the character or model in the message that presents information, provides evidence or demonstrates behavior. The messenger in the health messages plays a vital role in the act of persuasiveness by conducting in an attractive way, conveying credibility based on competence or trust, and having features that are relevant to the message he delivers.

There are two important qualities of source messengers in the health campaign message. These qualities are (1) increasing the scope of exposure by attracting intention in the cluttered media climate, and (2) facilitating comprehension via the customization or modeling of suggestions for unfamiliar or complicated health actions.

Selection of the messenger depends on the persuasion mechanism and the strategy, the tendencies of the target audience, and kind of message. To draw attention, health messages need to present characters, celebrities and public officials. Persuasion messages in health campaigns require experts for presenting proof, and experienced people for strengthened or cautionary role modeling.

\section{Quantitative Dissemination Factors}

Strategic message dissemination includes four major aspects: (1) the total volume of messages helps fulfill recognition, image formation, adequate and frequent exposure, and comprehension. Message saturation also shows the importance of the problem discussed in the campaign, that heightens agenda setting, (2) the amount of repetition facilitates messages comprehension and positive sensation toward the product, (3) the scheduling of message presentation depends on the situation. There are critical timing points in when the target audience is more possible to be active or attentive in searching for details, and (4) "temporal length of the campaign", the difficult task of obtaining the 
attention and obedience of audience often demands extraordinary consistency of an attempt for a long duration to obtain a large amount of exposures to result in influence. In many conditions, permanent campaigning is needful because the population need constant influence and regular reinforcement.

\section{Methodology}

The data analysis is based on Dillard and Shen's (2013) "Persuasive Strategies in Health Campaigns". A text from "COVID-19 - virtual press conference - 01 April 2020" has been chosen randomly to be analyzed in a qualitative descriptive method. To answer the research questions which read as: What are the persuasive strategies most frequently used in WHO COVID-19 Virtual Press Conferences? And, how are persuasive appeals employed to foster the persuasive process?, the following procedures are to be applied:

1- The text has been divided into 23 extracts (henceforth ET) that contain the persuasive strategies.

2- The persuasive strategies used in the selected data are identified and counted manually.

3- In terms of Dillard and Shen's (2013), "Persuasive Strategies in Health Campaigns", the persuasive strategies used in the selected data are analyzed to show how they are best used to foster persuasiveness process.

4- The persuasive strategies are then tabulated in order to show the percentages of their frequent use.

In the light of the results of data analysis, the research questions have been answered. On the basis of the outcome of these analyses, conclusions are finally drawn.

\subsection{Data Analysis}

ET.1

As we enter the fourth month since the start of the COVID-19 pandemic I'm deeply concerned about the rapid escalation and global spread of infection. Over the past 5 weeks we have witnessed a near exponential growth in the number of new cases, reaching almost every country,

territory, and area.

The speaker begins his argument with an incentive appeal; specifically the negative one, to show the danger of the situation. He wants to say that global spread of infection increases. He proves his claim by reporting the number of new cases in different countries, territories, and areas. The two techniques, incentive appeals and evidence, are used to reinforce the speaker's claim.

\section{ET.2}

The number of deaths has more than doubled in the past week. In the next few days we will reach one million confirmed cases, and 50,000 deaths. While relatively lower numbers of confirmed cases have been reported from Africa and from Central and South America, we realise that COVID-19 could have serious social, economic, and political consequences for these regions. It's critical that we ensure these counties are well equipped to detect, test, isolate and treat cases, and identify contacts.

The content of this message has many negative appeals to convey many ideas. These appeals include the following: (1) showing the critical condition via the doubled number of deaths and confirmed cases, (2) having some regions which are in need for support because COVID-19 could affect their social, economic, and political situations badly,(3) WHO is unable to ensure all necessary medical equipment to all countries because of the widespread of infection, and other countries and organizations should contribute in supporting such regions.

\section{ET.3}

I am encouraged to see that this is occurring in many countries, despite limited resources. Many countries are asking people to stay at home, and shutting down population movement, which can help to limit transmission of the virus, but can have unintended 
consequences for the poorest and most vulnerable people. I have called on governments to put in place social welfare measures to ensure vulnerable people have food and other life essentials during this crisis.

The speaker wants to motivate all countries to adopt the healthy behavior: staying at home, keeping the social distance, and restricting population movement to reduce the transmission of the virus by using an incentive, that is; many countries follow this healthy behavior in spite of the limited sources.

Another strategy used in this message is the "two-sided message". The speaker raises the problem that the healthy behavior could lead to unlikeable consequences for the poorest people. This problem could be tackled by governments via ensuring food and other essentials life for those people. This strategy is used to persuade the audience that such a problem can be tackled and to urge governments to take part in solving it.

\section{ET.4}

There is an ongoing debate about the use of masks at the community level. WHO recommends the use of medical masks for people who are sick, and those caring for them. However, in these circumstances masks are only effective when combined with other protective measures. WHO continues to gather all available evidence, and continues to evaluate the potential use of masks more broadly to control COVID-19 transmission at the community level. This is still a very new virus, and we're learning all the time.

The strategy of "two-sided message" is used again. Some issues are raised to achieve five persuasive messages. First, medical masks should be worn by sick people and those caring for them. Second, masks are not effective unless they are combined with other protective means.
Third, There are no enough pieces of evidence to confirm that wearing masks helps limit COVID19 transmission, but WHO is going on collecting evidence to prove or disprove that. Fourth, all recommendations and instructions produced by WHO are based on evidence. Fifth, Since, the virus is very novel, WHO does not know enough information about it and the process of investigation is going on.

\section{ET.5}

"As the pandemic evolves, so does the evidence, and so does our advice. But what doesn't change is WHO's commitment to protecting the health of all people, based on the best science, without fear or favour."

By using the strategy of "two-sided message", the speaker raises two issues to fulfill two persuasive messages. The first one is that the evidence is not fixed because the disease frequently evolves. Thus, WHO's advice is changeable too since the advice is mainly based on the evidence. The second is that WHO is committed to saving the health of all populations, based on the best scientific methods, as an ongoing process that does not concern fear or favour.

\section{ET.6}

"It's really, really important that all countries take this seriously, get ready, prepare their health system, strengthen their public health architecture, engage their communities, educate communities, and bring communities onboard and leave no one behind.'

The strategy of "quantitative dissemination factors' is used to enhance the act of persuasion. The adverb 'really' which modifies the adjective 'important' is repeated twice to persuade the audience of the importance of the message. The message emphasizes taking the matter seriously via getting ready, preparing the health system, etc. 
June 28, 2021 [Vol. 32(2)]

P-ISSN: 1680-8738; E-ISSN: 2663-547X

ET.7

"I'm going to pass to Maria on this because Maria has been tracking this one."

Since the messenger is very important in the process of persuasion, the presenter tries to define the messenger to the audience to increase the persuasiveness process. He shows that the messenger is specialized in such a field. Hence, the argument delivered by the messenger would be more persuasive.

ET.8

So with regards to the reporting of cases, our case definitions include laboratory confirmed cases regardless of the development of symptoms. Because we know that there are individuals who are followed up through contact tracing, and they're identified very quickly. And some of those individuals who are identified have not yet developed symptoms. And so it's important for us to capture those individuals as part of case detection, as part of surveillance.

The speaker raises the matter of identifying cases. He rebates it via defining the way in which WHO uses to identify such cases. He wants to assert that WHO depends heavily on laboratory confirmed cases without regard to the development of symptoms. He refutes the matter of symptoms and gives justification that some people who are diagnosed have not developed symptoms yet. He emphasizes that it is important for WHO to detect such cases because they would be more dangerous than those who have developed symptoms. The strategy used in this message is 'two-sided message'. It is used to achieve a persuasive message via rebating and refuting some matters.

ET.9

Because from data that we've seen from China, in particular, we know that individuals who are identified, who are listed as asymptomatic, about $75 \%$ of those actually go on to develop symptoms. So when we look at our language and we look at what proportion of the reported cases are asymptomatic, it's important to classify those as no symptoms and PCR positive, and then do not go on to develop symptoms.

In this message, two persuasive strategies are used. The first one is 'evidence'. The speaker gives a proof for his argument. He supports the information that he presents by reporting cases from china. The second strategy is 'message sources'. Since China is the first country that the virus appeared in, China would be more experienced than other countries. Thus, the message based on the data reported from chine could be more persuasive.

\section{ET.10}

"So again, our case definition includes laboratory confirmed cases regardless of the development of symptoms."

The speaker repeats his message again to show the importance of the message. The 'amount of repetition' is the factor that reinforces the act of persuasion because it shows the audience the extent of importance of the message.

\section{ET.11}

In this response, and in the fight against this pandemic, the role of political leaders is central. The role of business leaders is very, very important and central too. And the role of religious leaders and community leaders is very, very important. And we're reaching out to government leaders, political leaders, business leaders, religious leaders, and community leaders, and other influencers. It's through those leaders that we can reach out to all communities to take part in the fight. 
The incentive word 'fight' is used to show the critical situation and that there is an enemy that should be defeated. He urges people to be alert and exert hard efforts to overcome the epidemic. The word 'fight' indicates that the world in a war and a war requires global solidarity and sacrifices to confront the novel virus. The speaker also repeats the intensifier 'very' to explain the important role of leaders in different fields in stimulating people to take part in confronting the pandemic. He also repeats the word "fight" to convey a persuasive message that all the world should be in call up.

\section{ET.12}

"We've seen how this virus behaves in a number of countries and we need to prepare for that. That may happen in your country.

In order to stimulate people or countries to prepare themselves well, the speaker uses two strategies. First, he uses two negative appeals, "how this virus behaves" and "That may happen in your country", to motivate people or countries to get ready for that. Second, he uses evidence for that by citing the countries in which the virus has spread. Thus, the speaker uses both persuasive strategies 'evidence and negative

\section{ET.13}

appeals' to fulfill a persuasive message.

So there's some practical guidance that we have on our website related to clinical operations and getting your hospitals ready. Finding locations where you can treat mild patients versus severe patients. Readying your workforce so that you can have people who can identify cases and help with case finding and contact tracing. To help find where you can quarantine your contacts. So there is some practical information that's online, that's there to help you tailor that approach. And what Mike said around this, comprehensive measures to get yourselves ready and activate those systems now.
In this message, the speaker raises the matter of treating patients. The speaker tries to motivate people to resort to WHO's website designed for treating mild cases. The speaker wants to persuade people not to go to actual hospitals in mild cases in order to avoid the infection. He gives them a substitute, that is, they can contact and visit the website to help them diagnose and treat mild cases instead of going to actual hospitals. He motivates people to do so by using an implied 'negative appeal' that they will be more vulnerable to get the infection if they go to actual hospitals. He also uses an implied 'positive appeal', that is; they will be less vulnerable to the infection than those going to virtual hospitals. Moreover, the speaker tries to explain and clarifies the way in which people may consult WHO's website. He tries to facilitate the process by explaining the way of accessing such a website and what kind of information and people that they could find in order to help them identify and treat mild cases. $\mathrm{He}$ tries to make the message clear and understandable because 'understandability' is one of the qualities that enhances the persuasiveness act.

\section{ET.14}

We need to be very careful not to knee-jerk. We need to be very careful not to be changing policies every single day, because people on the frontline need certainty in their days. People, communities need some certainty. So it's really important that we are very consistent in our communication with communities and our frontline workers about what we do .

The speaker wants to show the authenticity and accuracy of the policy adopted by WHO. He asserts that by explaining the 'message sources'. $\mathrm{He}$ confirms that WHO's policy is based on frontline workers and those workers need days not a day to confirm something. Thus, it is difficult for WHO's policy to change every single day. By using 'message sources', the 
speaker tries to convince people with two ideas: the authenticity and accuracy of WHO and the difficulty of every single day-changing of WHO's policy.

\section{ET.15}

"And we need to give clear messages about what we do for the next week or the next two weeks".

This message is directed to WHO. The speaker wants to say that they need to schedule their message in order to be more persuasive because 'scheduling the message' is one of the factors that helps achieve the persuasion process.

\section{ET.16}

And we need to then be clear when we're going to evaluate the impact of that period of intervention. And then if we have to change, we change, and we communicate that clearly. And then we do it again for another two or three weeks. And then we see how that works. And then we gather the information and we consult with our frontline workers. And then if we have to adjust or change. This is about adapt, adjust, implement, measure, do it again. And you just have to keep doing that over and over and over again until you control the disease .

The speaker shows the way adopted by WHO in evaluating the situation of the period of intervention. He facilitates comprehension via personalization and modeling the complex way adopted in evaluating the situation. He gives details to make the content of the message clear, simple, and comprehensible as much as he can to enhance the act of persuasion. The quality of 'understandability' is used because it is one of the qualities of successful persuasive messages. ET.17

We see increases in testing. We're seeing an increase in surveillance, and we're seeing investment in the healthcare system to be able to deal with more cases. But it is certainly too early for anyone to determine the impact of the shutdown or lockdown measures on disease transmission at this point.

The speaker raises the matter of shutdown or lockdown to approve or disprove whether it has an effect on disease transmission or not. Through this message, the speaker shows that there is no proof that shutdown or lockdown affects the disease transmission in spite of increasing in testing and surveillance. He uses the strategy of 'two sided-message' to rebate the debate and refute the misinformation that confirms that shutdown or lockdown has an impact on disease transmission.

ET.18

"I will repeat with what I started.

This is a pandemic for the first time caused by a coronavirus, and whose behaviour is not really known. And we have to stand in unison to fight this unknown and dangerous virus".

The messenger repeats that the disease is the first ever epidemic in the world to emphasize the danger of this virus and it requires hard efforts to defeat it. The main idea that the messenger tries to persuade the communities of is that it is a very novel disease therefore many things about that virus are still unknown and need continuous efforts to be uncovered. He uses the technique of 'amount of repetition' to do that. ET.19

To look and see which actions are the most effective. We have evidence from Asia in terms of a number of countries now that have broken this down to sub-national levels to look at what has been done where. And what we've been saying about aggressively looking for cases, testing suspect cases, finding contacts, quarantining contacts, isolating patients, and caring for them depending on their severity, those work.

To show the most effective actions against COVID-19, the speaker tries to support his message by giving a proof for that. He explains 
that the most effective actions are "aggressively looking for cases, testing suspect cases, finding contacts, quarantining contacts, isolating patients, and caring for them depending on their severity". These effective actions are based on evidence from Asia in a number of countries. The speaker wants to persuade the audience by supporting his claim with evidence.

\section{ET.20}

So I would advise people that if you have your favourite remedy that you use, like honey, like lemon, like ginger, please continue to support yourself through the illness. But please, let us avoid making assumptions without evidence that certain things can cure COVID-19. At the moment there is no proven therapy for COVID-19.

The 'two sided-message' is used to raise the matter of therapy. The speaker use this strategy to assert two things. First, he encourages people to have honey, lemon, and ginger through the illness. Second, there is no evidence till this moment that supports the claim that such things can cure COVID-19. In this message, the speaker rebates the debate and refutes the misinformation to persuade people that there is no cure discovered till this moment.

\section{ET.21}

I'd like to ask how can individuals be persuaded that COVID-19 is a real threat, and what each person does makes a difference. Some people still don't understand that if they fail to follow the physical distancing rules they could be infecting other people that may lead to deaths further down the line. Or is it a case that some individuals need to be persuaded that what happens in their community as a whole is really important? And that a greater sense of local community needs to be established in order for them to take on physical distancing. That's my question.
Thank you for that question. I, I think you almost answered the question in your question, in the sense that COVID-19 is a real threat. It is a real threat to everyone on the planet. It's a new virus, which means everyone is susceptible to infection. It is a virus that causes disease in people, which range from some individuals will have mild disease, and a large proportion, 15\%, will have severe disease. Another 5\% will have critical disease. And some people will die.

In this message, the speaker realizes well that 'negative appeals' are one of the persuasive strategies used in health campaigns. Thus, he uses some negative appeals like a real threat, everyone is susceptible to infection, severe disease, critical disease, and some people will die, to persuade individuals that the virus is really danger and threatens all the world. He also tries to convince them that they must follow the healthy recommendations and physical distancing rules; otherwise, they would be infecting and this would lead to death cases. Negative appeals are repeated in both the question and answer to create a successful and persuasive message via utilizing two persuasive techniques: 'negative appeals' and 'amount of repetition.

ET.22

So many individuals who will develop severe disease are older, but we have seen in a number of countries that younger people are dying. I'm looking at data from Italy here, and we have individuals in their 30 s who are dying. We have individuals in their 40s, in their 50s, who are dying. This is a virus that can be very serious in individuals. And so it's a real threat. It not only has public health implications, but it has very strong social and economic implications. 
Three persuasive strategies are used in this message. The first one is 'two sided-message'. The speaker wants to explain the age of people who would die due to the pandemic. He tries to persuade individuals that not only will old people die, but also young will die too due to that disease. Thus, the controversy is rebated and the misinformation is refuted. The second strategy is 'evidence'. He claims that young people would die too due to that illness. He proves his claim by giving evidence that Italy that supports his claim to achieve a persuasive message. Thirdly, the speaker uses 'negative appeals', that the virus threatens not only public health, but also economic and social implications to persuade individuals that the virus is really serious.

ET.23

If you can prevent yourself from getting infected you could prevent onward transmission to someone who may be more vulnerable, who could develop more severe disease and die. And that is a responsibility that you have to yourself, to protect yourself, to protect your family, and to protect your community and your loved ones. And that is something that everybody needs to understand. Every person on the planet has a role to play here. And they need to feel empowered to be able to do something about that, to protect themselves.

Both negative and positive appeals are used to stimulate individuals to prevent people themselves from the infection. The negative appeal is that if they get infected, they will transmit the infection to a man who may be more susceptible to the infection and this would lead to his death. On the other hand, the positive appeal is that if they protect themselves, they will protect their families, communities, and loved ones. The two incentives are used to persuade people that every individual should take part in defeating this novel virus otherwise everyone will be at risk.
Table 1

The Frequencies and Percentages of Persuasive Strategies

\begin{tabular}{|c|c|c|}
\hline $\begin{array}{c}\text { Persuasive } \\
\text { Appeals }\end{array}$ & Frequency & Percentage \\
\hline $\begin{array}{c}\text { Incentive } \\
\text { Appeals }\end{array}$ & 14 & $36.8 \%$ \\
\hline Evidence & 5 & $13.1 \%$ \\
\hline $\begin{array}{c}\text { One-Sided Vs. } \\
\text { Two-Sided } \\
\text { Messages }\end{array}$ & 7 & $18.4 \%$ \\
\hline $\begin{array}{c}\text { Message } \\
\text { Qualities }\end{array}$ & 2 & $5.2 \%$ \\
\hline $\begin{array}{c}\text { Message } \\
\text { Sources }\end{array}$ & 3 & $7.8 \%$ \\
\hline $\begin{array}{c}\text { Quantitative } \\
\text { Dissemination } \\
\text { Factors }\end{array}$ & 7 & $18.4 \%$ \\
\hline Total & $\mathbf{3 8}$ & $\mathbf{1 0 0 \%}$ \\
\hline
\end{tabular}

\section{Findings and Discussion}

Actually, all persuasive strategies are important in persuasive discourses, but the field in which these persuasive strategies are applied makes some of them more appropriate than others. The findings or results of the study will be discussed based on the answers of two research questions postulated in section 1 , Introduction.

The data analysis revealed that most of the persuasive strategies proposed in the adopted model have been used, but in varying proportions. For instance, incentive appeals, specifically the negative ones have been mostly used. This is because the main dimensions of "incentive messages" include "physical health, legal, economic, social, psychological, and effort; each has potential positive and negative evaluations based on audience Predispositions". The dimension that is most frequently used in health campaigns is "physical health, with negatively valued threats" (particularly illness, injury and death). They are presented more often than "positive promises", such as wellness (Dillard \& Shen, 2013, p.285). People are usually motivated with a protection motivation to protect themselves from social, psychological and physical threats. Hence, negative appeals to 
health seem to be more persuasive than positive ones.

The two persuasive strategies mostly used after 'incentive appeals' are 'quantitative dissemination factors' and "one-sided versus two-sided campaign messages". This technique of 'quantitative dissemination factors' has four important factors that foster the persuasive process. These factors, "the total volume of messages, the amount of repetition, the scheduling of message presentation, and temporal length of the campaign", help fulfill recognition, image formation, adequate and frequent exposure, and comprehension. Hence. It is normally widely used in the such register to achieve persuasive messages.

Regarding the strategy of "one-sided versus two-sided campaign messages", although one-sided messages are widely used in health campaigns, the "two-sided message" are more widely used in such a domain. The reason behind this is that since COVID-19 is a novel disease, many things and information about the disease are still obscure. This has led to the prevalence of controversies, misinformation, and rumors among people. Hence, this strategy has been widely used in order to rebate some controversial issues and refute misinformation and rumors.

The strategy of 'Evidence' has ranked the third position among the persuasive strategies mostly used in the selected data. Evidence is an important strategy in persuasive discourses. An argument will become more persuasive if it is supported with a proof.

Finally, most persuasive strategies have been used in such a domain. Some important persuasive strategies have been widely used to achieve persuasive messages. These persuasive strategies have been efficiently used to enhance the persuasive process via using appropriate and motivational linguistic devices.

\section{Conclusions}

Persuasive strategies are copious, but the field in which they are applied determines the extent of their importance and appropriateness. In health field, the persuasive appeals that seem to be important and appropriate are numbered according to their frequent use:

1-Incentive Appeals: They include negative appeals, positive appeals and multiple appeals. These incentive appeals are widely used because physical health, legal, economic, social, psychological, and effort are the key dimensions of incentive messages. Each has possible positive and negative appraisals based on community predispositions.

2-Quanitative Dissemination Factors: There are four significant factors in this technique that facilitate the convincing phase. These variables, the total volume of messages, the amount of repetition, the scheduling of message presentation, and temporal length of the campaign, help to gain awareness, image creation, sufficient and regular exposure, and understanding.

3-One-sided vs. Two-Sided Messages: Onesided messages would constantly ignore the demerits and display only the case that supports or objects to the unhealthy prevalence of good conduct. This technique is mostly used in health campaigns. On the other hand, two-sided messages are used to remove exiting suspicions and potential threats by elevating and rebating the opposite state and using tactics such as disproving false information or decreasing the prominent drawback.

4-Evidence: Enhancing the argument with the proof that is relevant to the situation increases the persuasion process.

5-Message Sources: The messenger plays a vital role in the persuasion process. A messenger can achieve a persuasive message in an attractive way, providing evidence for his claim, presenting information based on credibility, and having features that are relevant to the message he delivers.

6-Message Qualities: There are five important qualities that enhance persuasive messages. Hence, persuasive messages should be credible, delivered in an attractive and engaging way, appropriate in content and 
stylistic devices, understandable, and motivational.

\section{References}

Abu Rumman, R. N. (2019). Persuasive strategies in Arabic religious discourse: Evidence from the Friday Sermons of Dr. Mohammad Rateb Al-Nabulsi. International Journal of Linguistics, 11(6), 1948-5425. Retrieved from http://www.macrothink.org/journa 1/index.php/ijl/article/download/1 5799/pdf. doi: 10.5296/ijl.v11i6.15799

Aditama, M. G. (2016). Persuasion in International Journals: Pragmatic Analysis (A Published Master Thesis). Muhammadiyah University of Surakarta. Retrieved from http://eprints.ums.ac.id/40530/1/ARTI KEL\%20PUBLIKASI\%20ILMIAH.

Al-Shekhly, L. R. \& Mohsin, M.H. (2013). Persuasion in blurbs as an advertising discourse (An Extracted Research of Master Degree thesis). Journal of the College of Education for Women, 2013(2), 170-179.

Baker, M. J., \& Churchill, G. A. (1977). The impact of physically attractive models on advertising evaluations. Journal of Marketing Research, 14(4), 538-555.

Charteris-Black, J. (2011). Politicians and rhetoric: The persuasive power of metaphor.(Second Edition). London: Springer.

Dillard, J. P., \& Shen, L. (Eds.). (2013). The Sage handbook of persuasion. USA: Sage.

Dow, J. (2015). Passions and persuasion in Aristotle's rhetoric. London: Oxford Aristotle Studies.

Ghazani, A. Z. (2016). Study of persuasive strategies in selected American presidential speeches. International Journal of Humanities and Cultural Studies (IJHCS), 3(2), 631-647. Retrieved from https://www.researchgate.net/publicati on/322664581_Study_of_Persuasive_ Strategies_in_Selected_American_Pre sidential_Speeches.

Heinrich, J. (2007). Thank you for arguing: What Aristotle, Lincoln, and Homer Simpson can teach us about the art of persuasion. London: Penguin Group.

Janam, I. J. (2019). A critical discourse analysis of the language of persuasion used in the election campaigns by American parliaments. Alustath, 58(4),33-46.

Retrieved

from http://alustath.uobaghdad.edu.iq/index.ph $\mathrm{p} / \mathrm{UJIRCO} /$ article/view/1017.

Kennedy, G. A. (1963). The art of persuasion in Greece. USA: Princeton.

Khalil, U., Islam, M., Chattha, S. A., \& Qazalbash, F. (2017). Persuasion and political discourse: A critical discourse analysis of Imran Khan's election speech (2013). Pakistan Vision, 18(2), 193-210. Retrieved

from https://www.researchgate.net/publication 1335681774_Persuasion_and_Political_ Discourse_A_Critical_Discourse_Analysi s_of_Imran_Khan's_Selected_Election_S peech.

Knowles, E. S., \& Linn, J. A. (Eds.). (2004). Resistance and persuasion. USA: Psychology Press.

Kouzouloglou, E. D. (2015). Power and persuasion: Critical discourse analysis in 1997 Tony Blair's victory speech. Retrieved from https://www.academia.edu/30239 950/POWER_AND_PERSUASIO N_CRITICAL_DISCOURSE_AN ALYSIS_IN_1997_TONY_BLAIR S_VICTORY_SPEECH. 
June 28, 2021 [Vol. 32(2)]

P-ISSN: 1680-8738; E-ISSN: 2663-547X

Nothstine, W. (1989). Influencing others a handbook of persuasive strategies. USA: Crisp Learning.

O’Hair, D., Wiemann, M., Mullin, D. I., \& Teven, J. (2015). Real communication: An introduction. Third Edition. USA: Bedford/St. Martin's.

O'Shaugnessy, J., \& O'Shaughnessy, N. (2003). Persuasion in advertising. London: Routledge.

Pelclová, J., \& Lu, W. L. (Eds.). (2018). Persuasion in public discourse: Cognitive and functional perspectives (Vol. 79). Amsterdam: John Benjamins Publishing Company.

Petty, R. E., \& Cacioppo, J. T. (1986). The elaboration likelihood model of persuasion: In communication and persuasion (pp. 1-24). New York: Springer.

Smith, D. (2014). Banned mind control techniques unleashed. Retrieved from https://www.amazon.com/Banned-MindControl-TechniquesUnleashed/dp/150328672X.

Teven, J. J., \& Winters, J. L. (2007). Pharmaceutical representatives' social influence behaviors and communication orientations: Relationships with adaptive selling and sales performance. Human Communication, 10, 465-486.

Waad, M., \& Al-Bahrani, R. H. (2020). A cognitive linguistic study of non-verbal persuasive strategies in selected Iraqi and Malaysian tourism brochures. Journal of Education College Wasit University, 2(40), 657-676.

Worthington, I. (Ed.). (1994). Persuasion: Greek rhetoric in action. London: Routledge. 